\title{
Depletion of the thiol oxidoreductase ERp57 in tumor cells inhibits proliferation and increases sensitivity to ionizing radiation and chemotherapeutics
}

\author{
Melanie Hussmann ${ }^{1, *}$, Kirsten Janke ${ }^{1, *}$, Philip Kranz ${ }^{1}$, Fabian Neumann1, Evgenija \\ Mersch $^{1}$, Melanie Baumann ${ }^{1}$, Kirsten Goepelt ${ }^{1}$, Ulf Brockmeier ${ }^{1}$, Eric Metzen ${ }^{1}$ \\ ${ }^{1}$ Institut für Physiologie, Universität Duisburg-Essen, Hufelandstraße 55, D45122 Essen, Germany \\ *These authors have contributed equally to this work \\ Correspondence to: \\ Eric Metzen, e-mail: eric.metzen@uni-due.de \\ Keywords: endoplasmic reticulum, ER chaperone, unfolded protein response, p53, apoptosis \\ Received: July 15, 2015 \\ Accepted: October 08, 2015 \\ Published: October 21, 2015
}

\section{ABSTRACT}

Rapidly growing tumor cells must synthesize proteins at a high rate and therefore depend on an efficient folding and quality control system for nascent secretory proteins in the endoplasmic reticulum (ER). The ER resident thiol oxidoreductase ERp57 plays an important role in disulfide bond formation. Lentiviral, doxycycline-inducible ERp57 knockdown was combined with irradiation and treatment with chemotherapeutic agents. The knockdown of ERp57 significantly enhanced the apoptotic response to anticancer treatment in HCT116 colon cancer cells via a p53-dependent mechanism. Instead of a direct interaction with p53, depletion of ERp57 induced cell death via a selective activation of the PERK branch of the Unfolded Protein Response (UPR). In contrast, apoptosis was reduced in MDA-MB-231 breast cancer cells harboring mutant p53. Nevertheless, we observed a strong reduction of proliferation in response to ERp57 knockdown in both cell lines regardless of the p53 status. Depletion of ERp57 reduced the phosphorylation activity of the mTOR-complex1 (mTORC1) as demonstrated by reduction of p7056K phosphorylation. Our data demonstrate that ERp57 is a promising target for anticancer therapy due to synergistic p53-dependent induction of apoptosis and p53-independent inhibition of proliferation.

\section{INTRODUCTION}

One of the major challenges of current cancer treatment is the resistance of tumor cells to ionizing radiation (IR) and chemotherapeutical substances. In an urgent need for new drug targets the endoplasmic reticulum (ER) has become a promising candidate since rapidly growing tumor cells upregulate their protein synthesis and therefore depend on efficient folding of nascent secretory proteins in the ER. A set of molecular chaperones such as $\mathrm{BiP}$, calreticulin (CRT), protein disulfide isomerase (PDI) and GRP94 is mandatory to maintain the critical ER balance [1]. To avoid the accumulation of misfolded proteins, these are bound by molecular chaperones, transferred to the ER-associated degradation pathway (ERAD) and get disposed of by the proteasome $[2,3]$.

One survival mechanism of cells under stress conditions is the activation of the Unfolded Protein
Response (UPR) through one of its three ER-stress sensors IRE1, PERK and ATF6. Aim of the UPR is to re-establish ER homeostasis through reduction of protein synthesis and simultaneous overexpression of ER chaperones [4]. Depending on the severity and duration of ER stress, the UPR can be cytoprotective or induce apoptosis. Since the apoptotic response in cancer cells is often attenuated or even abrogated, this complex ER network becomes an important pathway which supports growth $[5,6]$. Activation of the UPR can occur after general and reversible attenuation of protein synthesis via eIF $2 \alpha$ phosphorylation which is summarized as the Integrated Stress Response (ISR) [7]. In addition to PERK, the ISR can also be mediated by other kinases upon amino acid starvation, viral infection, iron deficiency and oxidative stress. Activation of the ISR results in the synthesis of UPR target genes through increased eIF $2 \alpha$-independent translation of the transcription factor ATF4. Activation of at least one branch of the UPR has been reported in a number 
of human tumor samples [8]. Consequently, ER chaperones become an attractive target in cancer cells [9, 10]. For instance, the knockdown of BiP enhanced doxorubicininduced apoptosis not only in proliferating HEp3 cells, but also in a dormant subgroup which usually shows high resistance to chemotherapeutic treatment [11].

The ER provides a more oxidizing environment than the cytosol favoring formation of disulfide bonds in nascent exoproteins which is crucial for their stability and functionality. More than 20 members of the PDI family introduce disulfide bonds into client proteins and catalyze rearrangement of incorrectly formed disulfide bonds. The most prominent member of the PDI family is PDIA1 which exerts oncogenic and pro-survival functions in different cancer types $[12,13]$. Interestingly, novel potent PDI inhibitors are being developed, but their clinical value has yet to be proven [14-16]. The closest homologue of PDI is the thiol oxidoreductase ERp57 (GRp58/1,25D3MARRS Receptor/PDIA3), best known for its structural role in the assembly of the MHC class I molecule [17]. However, similar to PDI, it affects disulfide bond formation and reformation in the processing of numerous client proteins [18]. Both PDI and ERp57 are composed of four distinct domains $\mathrm{a}, \mathrm{b}, \mathrm{b}$ ' and a' forming a horseshoe shape where the $a$ and $a$ ' domains carry the active site CGHC and the $b^{\prime}$ domains of both enzymes contain the substrate binding site [19]. Of note, despite its C-terminal ER retention signal (QEDL), ERp57 was found in the cytoplasm as an interaction partner of mTOR [20] and
STAT3 [21] as well as in the nucleus involved in DNA binding $[22,23]$ and on the cell surface $[24,25]$.

Although some of the localization and functional studies of ERp57 are not entirely conclusive, ERp57 turned out to be a much more important player than originally anticipated with a cellular impact beyond the ER. Of particular interest is the report of an siRNAmediated knockdown of ERp57 that increased cell death in two human cancer cell lines initiated by the synthetic drug fenretinide [26] although the authors did not address the question how downregulation of ERp57 was actually linked to apoptosis. Here, we tested the potential benefit of targeting ERp57 in the human cancer cell lines HCT116 and MDA-MB-231 in combination with irradiation and chemotherapeutic compounds.

\section{RESULTS}

\section{ERp57 modulates apoptosis in response to anticancer treatment}

Lentiviral doxycycline-inducible ERp57 knockdown displayed an efficiency of $80-90 \%$ on average. Suppression of ERp57 significantly and consistently increased apoptosis in HCT116shERp57 (Fig. 1 and 2A). In contrast, induction of apoptosis following ERp57 knockdown in MDA-MB-231shERp57 cells was observed to vary between no effect and a slight protection against apoptosis (Fig. 1 and 2A).

\section{MDA-MB-231 p53 R280K}

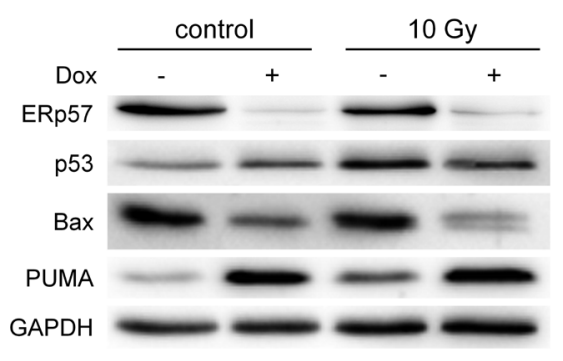

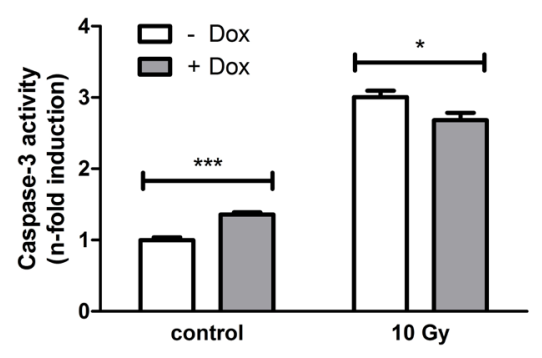
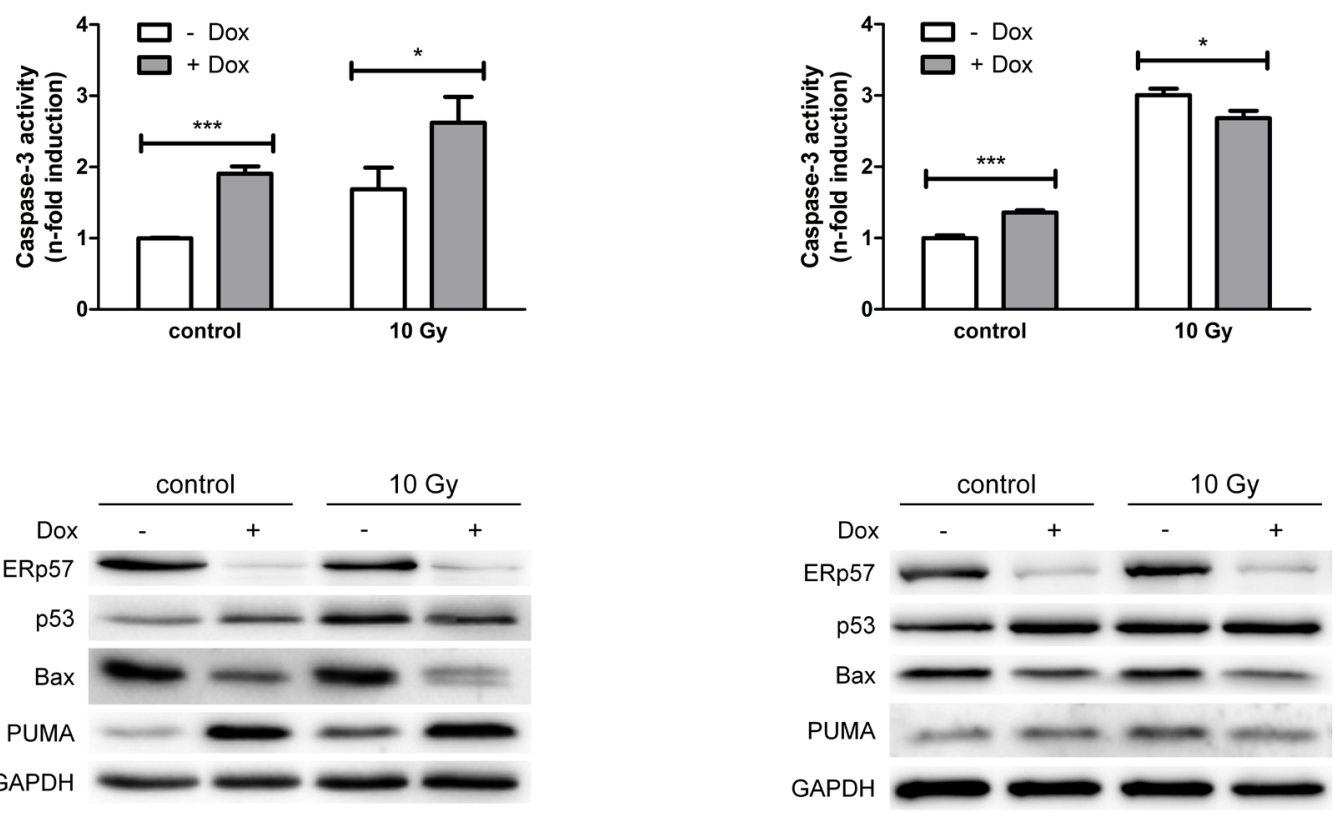

Figure 1: ERp57 modulates irradiation-induced apoptosis in a cell-type specific manner. HCT116shERp57 and MDA-MB-231shERp57 were irradiated with $10 \mathrm{~Gy} 24 \mathrm{~h}$ after induction of the ERp57 knockdown. $72 \mathrm{~h}$ after irradiation whole cell extracts were tested for caspase-3 activity (upper panel). In parallel, total cell lysates were subjected to Western blotting (lower panel). 
Following IR the cell lines showed different responses to depletion of ERp57. Wild-type p53 expressing HCT116shERp57 cells displayed enhanced sensitivity to irradiation-induced apoptosis while MDAMB-231shERp57 cells harbouring mutant p53 (R280K) were protected against irradiation-induced apoptosis after knockdown induction (Fig. 1). In HCT116shERp57 cells p53 was induced by both knockdown of ERp57 and IR whereas the combined treatment did not further increase p53 levels.

However, while the pro-apoptotic p53 target Bax was reduced following suppression of ERp57 (Fig. 1), another pro-apoptotic p53 target, PUMA, was strongly induced. In MDA-MB-231shERp57 the induction of p53 and PUMA following ERp57 knockdown was much less pronounced (Fig. 3C). Reduced apoptosis correlated with reduced Bax protein levels in MDA-MB-231 which is in line with the differing effects on apoptosis induction.

Following etoposide treatment similar effects of ERp57 knockdown were observed. In line with a protective effect of ERp57 in HCT116shERp57, these cells showed increased etoposide-induced apoptosis after doxycycline treatment. In contrast, MDA-MB231 shERp57 cells were protected against etoposideinduced apoptosis upon ERp57 knockdown (Fig. 2A). These alterations were also reflected by changes in early and late apoptotic/necrotic fractions of the cells upon double staining with annexin $\mathrm{V}$ and propidium iodide (PI) (Fig. 2B). While knockdown of ERp57 increased the apoptotic fraction from $22 \%$ to $35 \%$ in untreated HCT116shERp57 cells, these changes were not observed in MDA-MB-231shERp57 cells. Treatment with $50 \mu \mathrm{M}$ etoposide without knockdown induced apoptosis to a similar extent of approximately $50 \%$ in both cell lines, whereas suppression of ERp57 induced opposite effects in the two cell lines when combined with etoposide. In HCT116shERp57 cells combined treatment increased the apoptotic fraction from $54 \%$ to $72 \%$. In contrast, suppression of ERp57 reduced etoposide-induced apoptosis from $45 \%$ to $24 \%$ in MDA-MB-231shERp57 cells. Similar to the results observed for IR, apoptosis induction in HCT116shERp57 correlated with the induction of p53 and PUMA while the amount of Bax protein was not altered (Fig. 2C). In MDA-MB231shERp57 cells ERp57 suppression did not lead to pronounced changes in p53 and PUMA although PUMA was strongly induced following treatment with etoposide. Interestingly, Bax was generally reduced upon ERp57 knockdown in the breast cancer cells which coincided with the reduction of apoptosis particularly upon treatment with etoposide where a reduction of apoptosis and Bax protein was observed. The apoptotic response of HCT116shERp57 cells to 5-fluorouracil was similar to the response to etoposide (Fig. 2D, 2E and 2F).

\section{Knockdown of ERp57 activates the PERK branch of the UPR selectively}

To assess whether the apoptotic response in HCT116 cells is caused by unfolded proteins in the ER, all branches of the UPR were tested following suppression of ERp57 in untreated and irradiated cells. Although an induction of ATF 4 and eIF $2 \alpha$ phosphorylation at Ser51 was observed which indicates inhibition of protein translation (Fig. 3A), an induction of XBP1reporter gene activity or mRNA splicing (Fig. 3B) or ATF6 (Fig. 3C) reporter gene activity was not detectable. ER-stress has been reported to activate the JNK-pathway via IRE1 [27]. However, we were not able to detect stimulation of the JNK pathway after depletion of ERp57 (Fig. 3D). Together with the activation of ATF4 (Fig. 3A) these results point to a selective activation of the PERK branch of the UPR. In addition, increased expression of the abundant ER chaperone and ERAD component GRP94 (Fig. 3E) was detectable. Upregulation of PDI (Fig. 3G) or calreticulin or calnexin (Fig. 3H) were undetectable and induction of $\mathrm{BiP}$ occurred only inconsistently upon ERp57 knockdown (Fig. 3A and 3G). In irradiated cells we detected similar phosphorylation levels of eIF $2 \alpha$ and a similar increase in GRP94 as observed after ERp57 suppression. Following ERp57 inhibition and irradiation the more pronounced induction of eIF $2 \alpha$ phosphorylation and ATF4 protein expression demonstrated a further increase in ER stress levels (Fig. 3E). However, ATF6 activity and further induction of BiP protein levels were not detectable after knockdown of ERp57 in irradiated cells (Fig. 3A and 3C). Interestingly, GRP94 expression further increased under these conditions (Fig. 3E). To examine a direct involvement of the activated PERK branch in the apoptotic response, we treated the cells with the specific PERK inhibitor GSK2656157 [28]. The inhibitor reduced caspase-3 activity, phospho-p53 and PUMA (Fig. 3F and 3G). Of note, different results were obtained for the two pro-apoptotic factors after ATF4 activation: while CHOP remained low or was even decreased, GADD34 was elevated (Fig. 3G). Taken together these results indicate that depletion of ERp57 does not induce apoptosis via full activation of the UPR but enables selective activation of the PERK branch which triggers the induction of cell death.

\section{Loss of ERp57 promotes apoptosis in a p53-dependent manner}

To prove that the induction of apoptosis is indeed dependent on p53, the isogenic HCT116 cell line deficient for $\mathrm{p} 53$ was tested for the response to IR in the presence and absence of ERp57. HCT116shERp57 p53 -/- cells showed a less prominent increase in apoptosis after ERp57 knockdown induction as compared to p53 wild-type cells 
A

HCT116 p $53+/+$
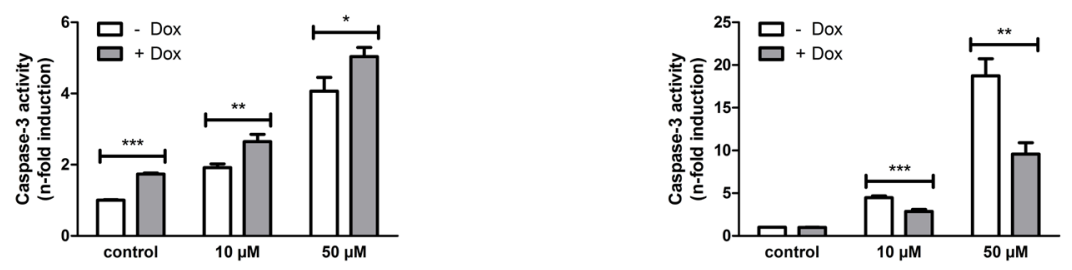

B

HCT116 p53 +/+
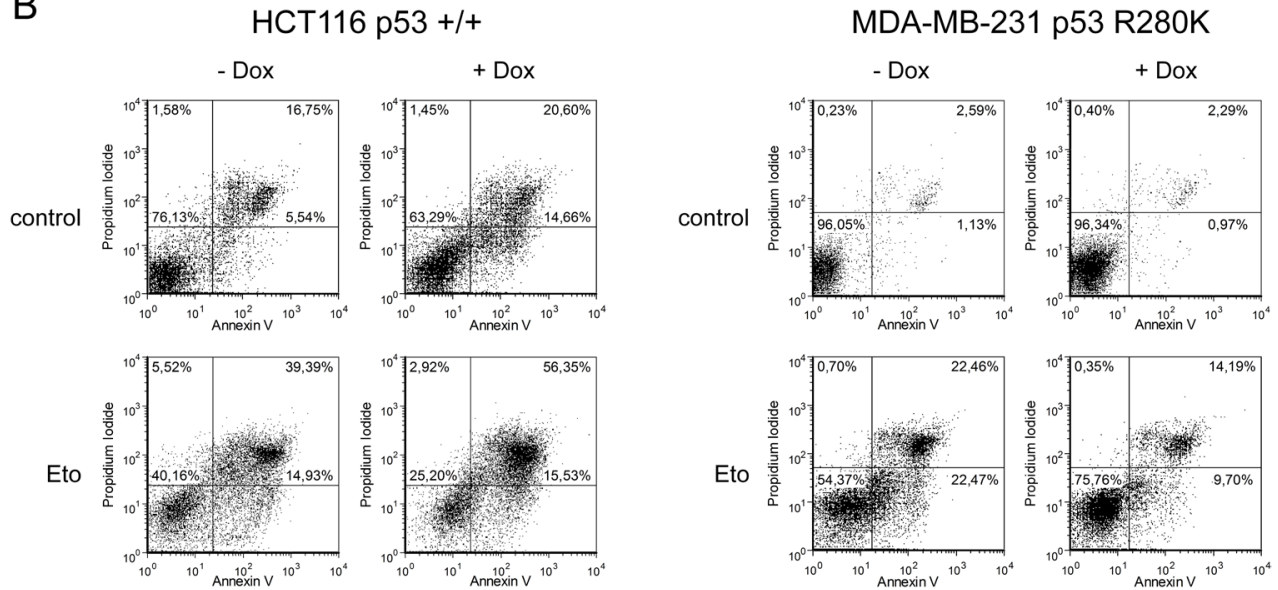

C

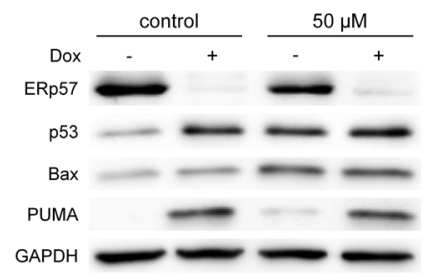

D

HCT116 p53 +/+

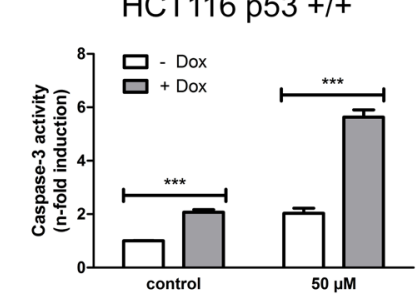

E
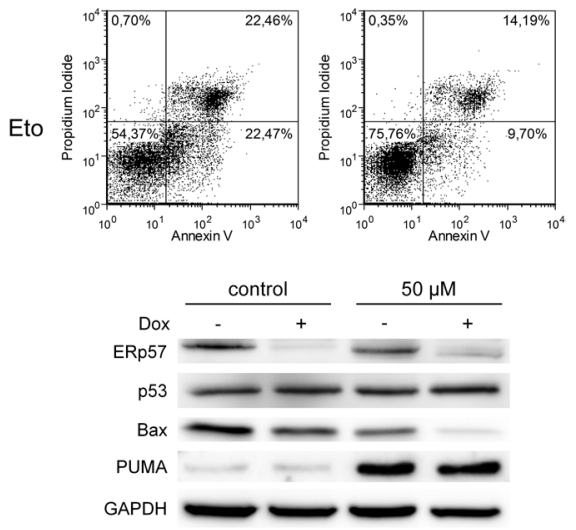

F
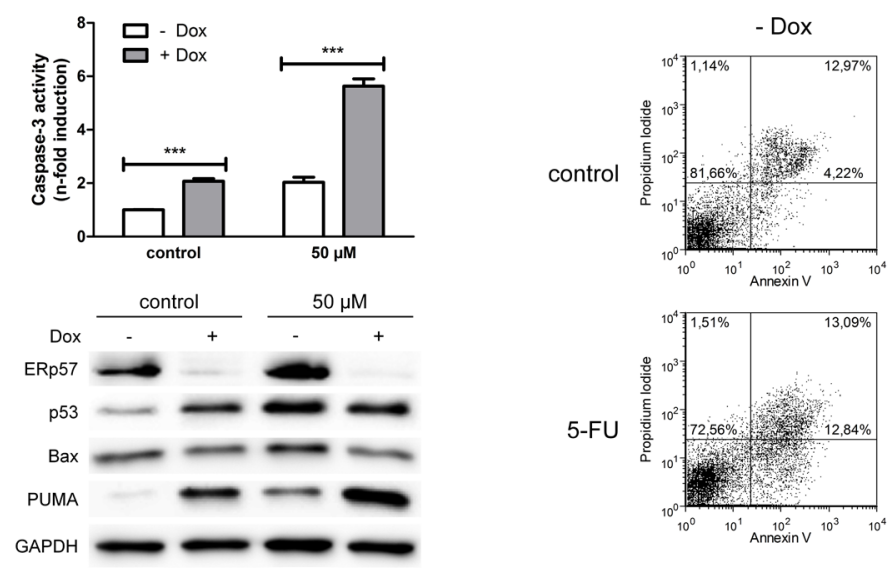

HCT116 p53 +/+
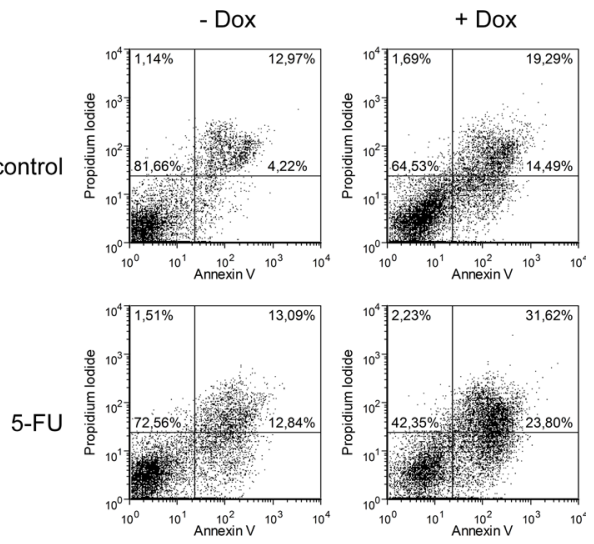

Figure 2: ERp57 modulates chemotherapy-induced apoptosis in a cell-type specific manner. For all chemotherapy experiments control cells were treated with vehicle only (DMSO). A. Apoptosis was triggered in inducible HCT116shERp57 and MDAMB-231shERp57 by treatment with etoposide $24 \mathrm{~h}$ after induction of the ERp57 knockdown. $48 \mathrm{~h}$ after treatment whole cell extracts were tested for caspase-3 activity. B. Cells were treated with $50 \mu \mathrm{M}$ etoposide (Eto) $36 \mathrm{~h}$ after induction of ERp57 knockdown. $48 \mathrm{~h}$ after treatment apoptosis was quantified by staining with annexin V and PI and subsequent FACS analysis. Representative data of two experiments are shown. C. Cells treated as in (B) were subjected to Western blotting. D. Cells were treated with $50 \mu \mathrm{M}$ 5-fluorouracil (5-FU) $24 \mathrm{~h}$ after induction of the ERp57 knockdown. $48 \mathrm{~h}$ after treatment caspase-3 activity was quantified. E. Cells were incubated with $50 \mu \mathrm{M}$ 5-fluorouracil $36 \mathrm{~h}$ after induction of ERp57 knockdown. $48 \mathrm{~h}$ after treatment cells were stained with annexin $\mathrm{V}$ and PI for FACS. Representative data of two experiments are shown. F. In parallel, cell lysates were analysed by Western blotting. 
A

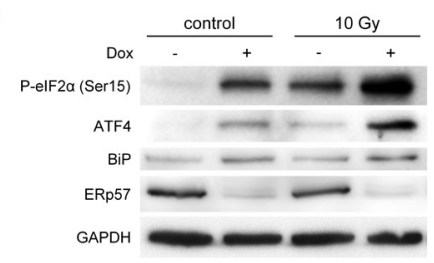

B
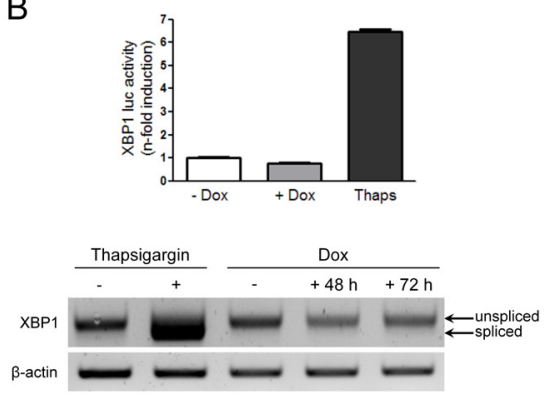

C
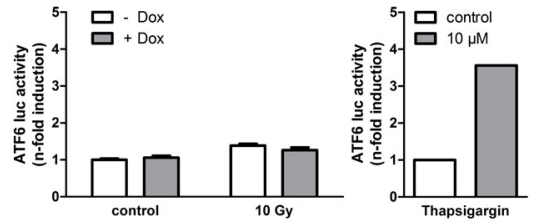

D

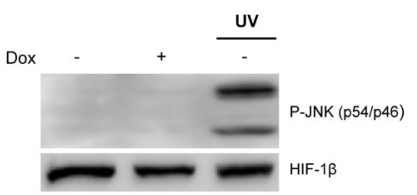

$\mathrm{E}$

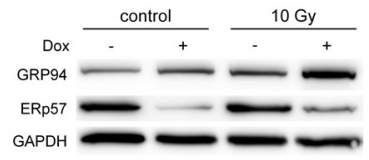

$\mathrm{F}$

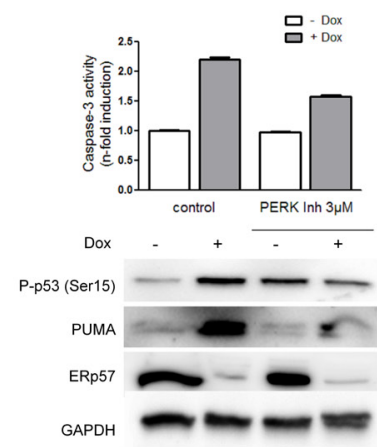

G

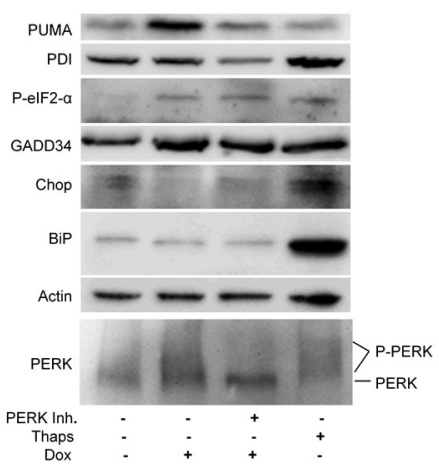

$\mathrm{H}$

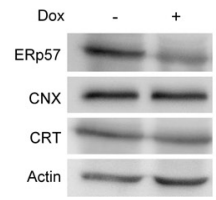

Figure 3: Knockdown of ERp57 in HCT116 cells activates the UPR exclusively via PERK. A. Inducible HCT116 shERp57 cells were irradiated with $10 \mathrm{~Gy} 24 \mathrm{~h}$ after induction of ERp57 knockdown. $72 \mathrm{~h}$ after irradiation the cells were lysed and subjected to Western blotting. P-eIF2 $\alpha$ (Ser51), ATF4 and BiP protein levels were monitored as indicators of ER-stress, GAPDH served as a loading control. B. XBP1 splicing as an indicator for IRE1 activation was analysed with a luciferase reporter gene assay (upper panel). Cells were transfected with the pXBP1u-FLuc reporter plasmid $24 \mathrm{~h}$ after induction of ERp57 knockdown and harvested $48 \mathrm{~h}$ later. Firefly luciferase activity was normalized to renilla luciferase activity. As a positive control for ER stress, cells were treated with $10 \mu \mathrm{M}$ thapsigargin for $24 \mathrm{~h}$. Lower panel: total RNA was subjected to RT-PCR and analysed for XBP1 splicing. $\beta$-actin served as a loading control. C. $24 \mathrm{~h}$ after knockdown induction, the cells were transiently transfected with an ATF6-luciferase reporter gene construct. After $48 \mathrm{~h}$ lysates were prepared and analysed by luciferase activity detection. D. $96 \mathrm{~h}$ after induction of ERp57 knockdown, P-JNK was detected by Western blotting as an indicator of IRE1 activation. Hif-1 $\beta$ was used as a loading control and UV-treated cells as a positive control for JNK activation. A representative Western blot from two independent experiments is shown. E. Cells were treated as in (A) and tested for GRP94 as an indicator of ERAD, GAPDH served as a loading control. F. After ERp57 knockdown induction and treatment with $3 \mu \mathrm{M}$ PERK inhibitor for $96 \mathrm{~h}$, cell extracts were tested for caspase-3 activity (upper panel). Representative data of two experiments are shown. In parallel, cell lysates were subjected to Western blotting (lower panel). Representative Western blots from two experiments are shown. G. Cells were treated as in (F) Cell lysates were analysed by Western blotting. Phosphorylated PERK is detected as a higher molecular weight smear. Western blots from two independent experiments are shown. H. After ERp57 knockdown induction for $96 \mathrm{~h}$, cell lysates were analysed by Western blotting. A representative Western blot from two independent experiments is shown. 
(Fig. 4A). In addition, ERp57-dependent changes were not observed in irradiation-induced apoptosis in p53-deficient cells. Wild-type p53 induced in HCT116shERp57 cells upon treatment with doxycycline was phosphorylated at Ser15 demonstrating targeted activation of the tumor suppressor (Fig. 4B). In addition, the induction of PUMA observed in the p53 +/+ cells was not present upon depletion of ERp57 in p53-deficient cells while Bax protein levels were strongly reduced (Fig. 4B).

To further investigate whether a direct interaction between p53 and ERp57 is involved in protection against apoptosis, p53 was immunoprecipitated from untreated and irradiated HCT116 cells. ERp57 was undetectable in p53 pulldown samples while the known interaction partner MDM2 co-precipitated with p53 (Fig. 5A).

As ERp57 contains a potential nuclear localization signal (Fig. 5B) and has previously been described to be located not only to ER and cytoplasm but also to the nucleus $[22,29]$, we tested whether ERp57 is involved in transcriptional regulation. Thus, a GFPtagged fusion protein was introduced into HCT116 to determine the subcellular localization of ERp57 (Fig. 5B).
Counterstaining of ER and nucleus demonstrated that ERp57-GFP is localized in the perinuclear space but not inside the nucleus in HCT116 cells (Fig. 5C). False positive signals in the nucleus were disproven by z-stack confocal microscopy. A fraction of the protein localized to the cytoplasm as demonstrated by permeabilisation of the plasma membrane with digitonin. Importantly, the integrity of ER membranes was not compromised as the ER resident protein BiP was not extracted (Fig. 5D). The extraction of cytoplasmic fluid was proven by detection of GAPDH.

\section{ERp57 triggers proliferation of cancer cells independent of the p53 status}

Next, we examined the impact of ERp57 on cell cycle progression of HCT116 and MDA-MB-231. In both cell lines knockdown of ERp57 induced cell cycle arrest in the G2-phase while the amount of cells in the G0/ G1-phase was reduced (Fig. 6A). For HCT116shERp57 cells the effect of combined treatment with irradiation and knockdown of ERp57 on G2 arrest was more pronounced
A HCT116 p53 +/+

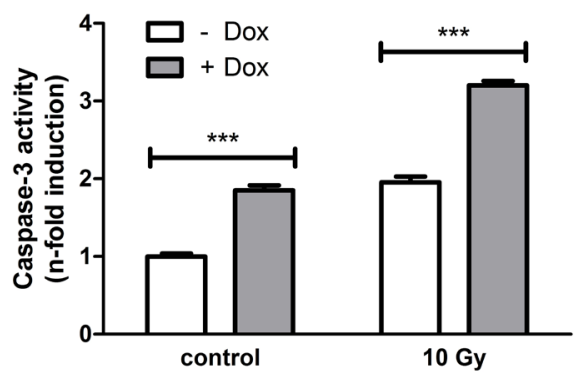

B

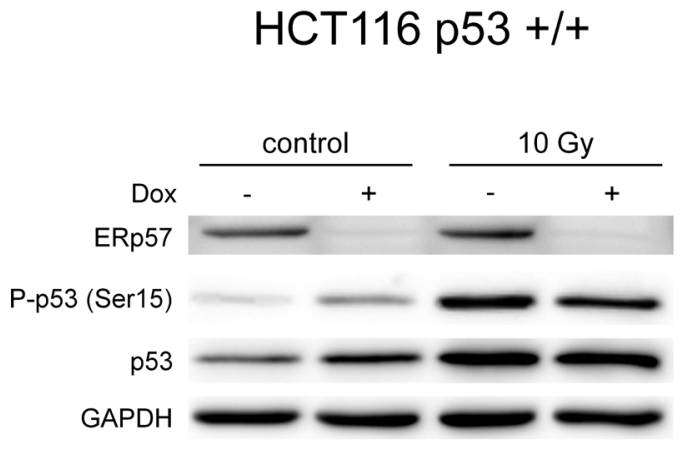

HCT116 p53 -/-

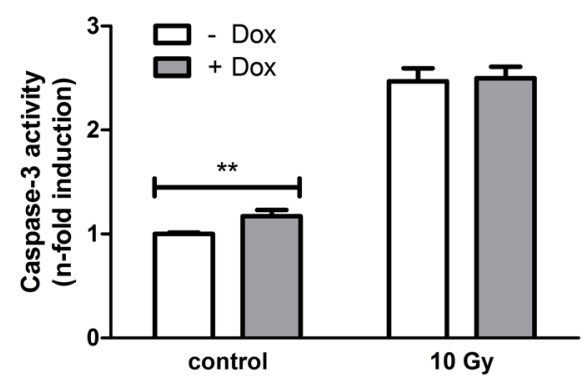

HCT116 p53 -/-

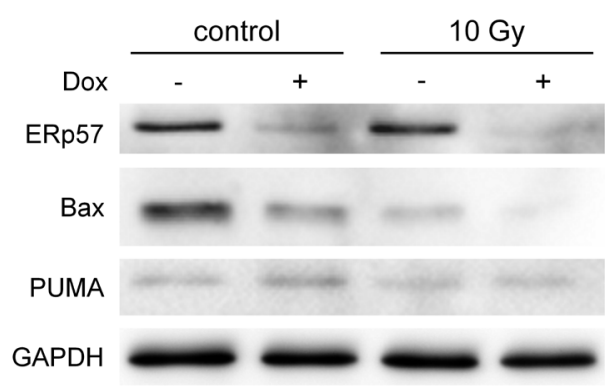

Figure 4: Loss of ERp57 induces p53-dependent apoptosis. A. Apoptosis was triggered in inducible HCT116 shERp57 p53 +/+ and p53 -/- cells by irradiation with 10 Gy $24 \mathrm{~h}$ after induction of ERp57 knockdown. $72 \mathrm{~h}$ after irradiation caspase-3 activity was measured. B. In parallel, total cell lysates were subjected to Western blotting. 
A

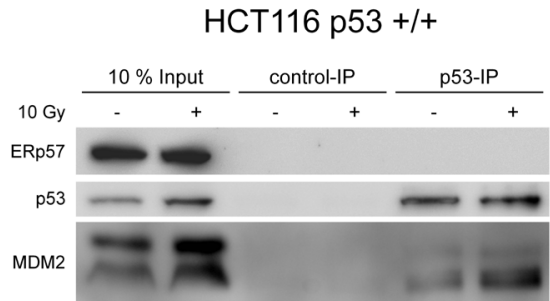

B

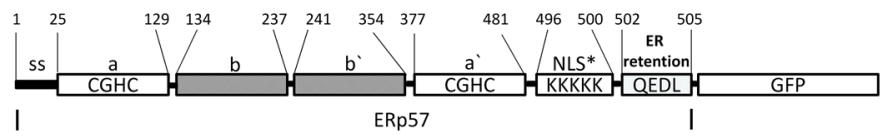

C

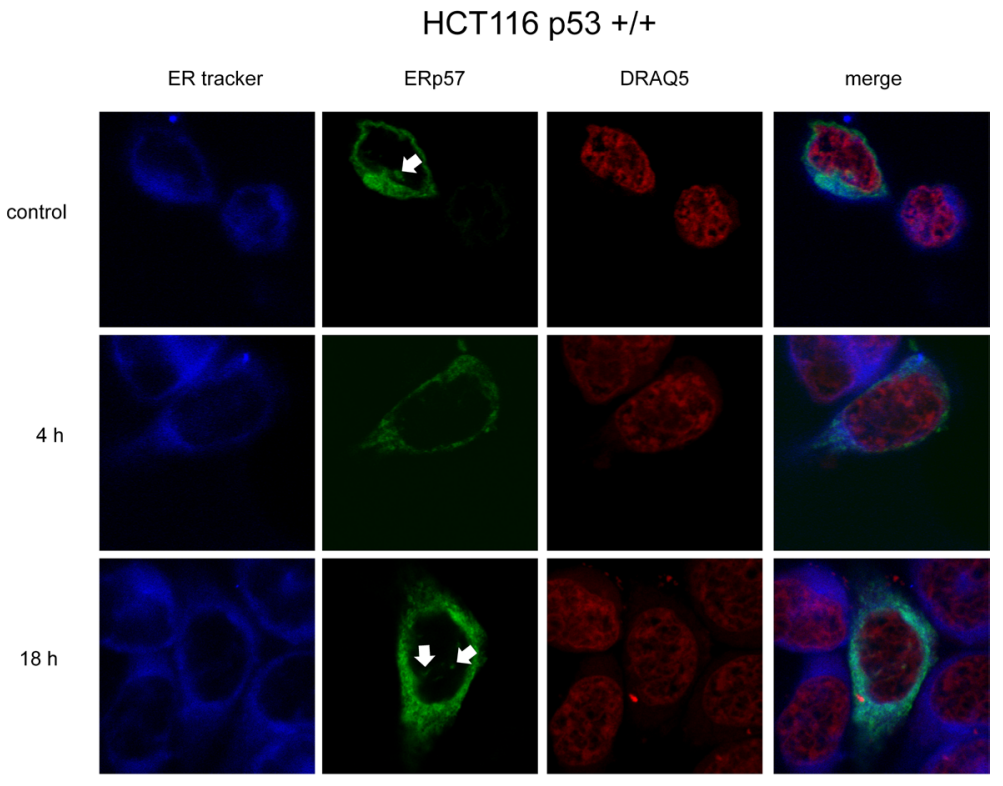

D

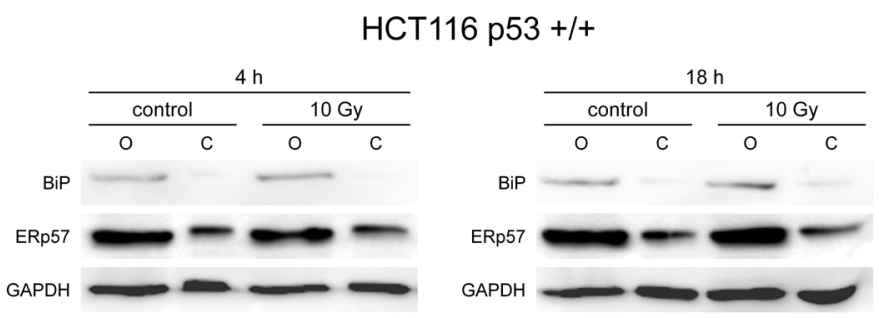

Figure 5: ERp57 and p53 do not interact directly. A. Whole cell lysates were prepared from HCT116 cells $24 \mathrm{~h}$ following treatment with $10 \mathrm{~Gy}$ and subjected to immunoprecipitation of p53. ERp57 was not detectable by immunoblotting in contrast to MDM2. As a negative control immunoprecipitation was performed with an isotype control IgG. B. Domain structure of the ERp57-GFP fusion protein used for fluorescence localization. NLS*: potential nuclear import signal, SS: signal sequence. C. Fluorescence of ERp57-GFP. $24 \mathrm{~h}$ following transient transfection with ERp57-GFP (green) HCT116 cells were exposed to $10 \mathrm{~Gy}$ and fixed at the indicated time points. ER and nucleus were counterstained with ER-tracker (blue) and DRAQ5 (red), respectively. Arrows point to spurious nuclear signals. D. Subcellular fractionation showing the subcellular localization of endogenous ERp57. HCT116 cells were exposed to 10 Gy and subcellular fractionation with digitonin was performed at the indicated time-points to separate the cytoplasm (C) from the organelle fraction (O) BiP was monitored as a marker for the organelle fraction while GAPDH indicates extraction of cytoplasm. 
A

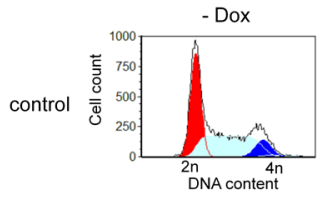

10 Gy
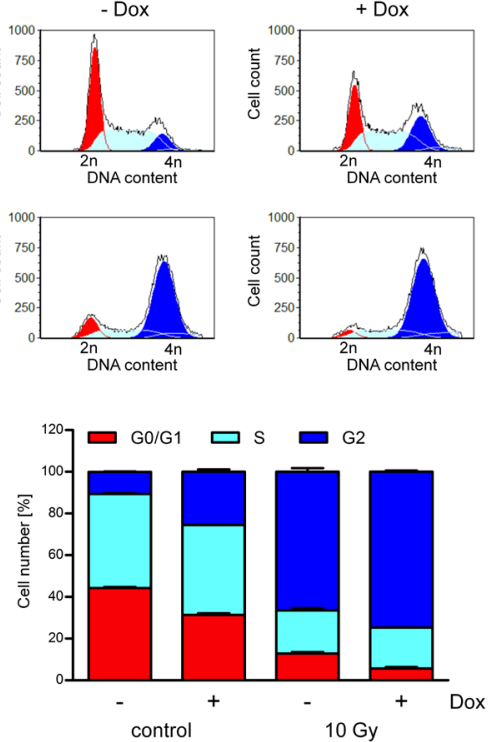

B

HCT116 p53 +/+

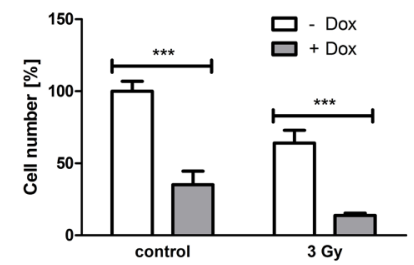

C

HCT116 p53 +/+
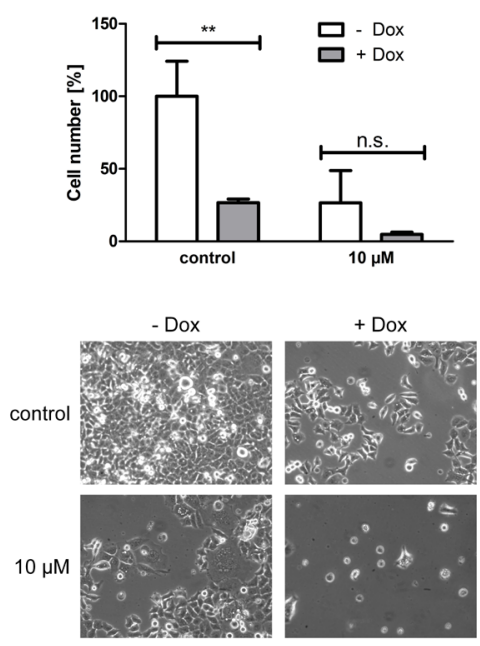

MDA-MB-231 p53 R280K
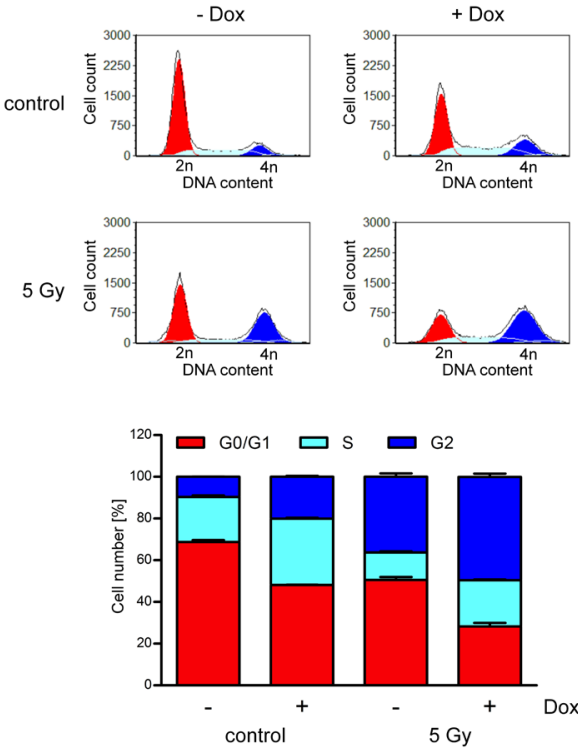

MDA-MB-231 p53 R280K

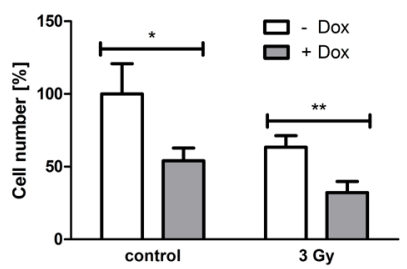

MDA-MB-231 p53 R280K
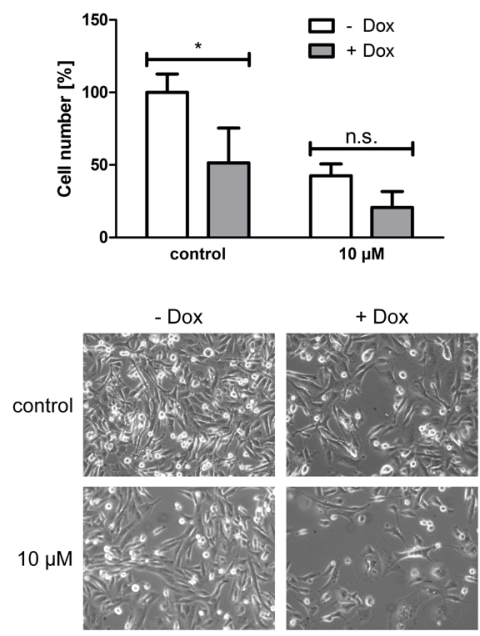

Figure 6: ERp57 triggers proliferation and cell cycle progression of cancer cells independently of p53. A. Inducible HCT116 shERp57 and MDA-MB-231 shERp57 were irradiated $48 \mathrm{~h}$ after induction of ERp57 knockdown. $24 \mathrm{~h}$ after irradiation cell cycle distribution (upper panel) was determined by PI staining and subsequent FACS analysis. In the lower panel fractions of the cells in each cell cycle phase are plotted. Representative data of two independent experiments are shown. B. 4d after knockdown induction HCT116 shERp57 and MDA-MB-231 shERp57 cells were irradiated with 3 Gy. Following treatment cells were reseeded. Cell numbers were determined when the control samples had grown to confluency and normalized to non-induced controls. C. $5 \mathrm{~d}$ after knockdown induction, cells were treated with $10 \mu \mathrm{M}$ etoposide for $4 \mathrm{~h}$. Cell numbers were determined as in (B) Images of representative samples were taken prior to counting. 
than for MDA-MB-231 cells. Similar results were obtained for cellular proliferation. For both cell lines cell numbers were significantly reduced upon knockdown of ERp57 (Fig. 6B). Upon incubation with $10 \mu \mathrm{M}$ etoposide cell numbers were not significantly altered by suppression of ERp57 (Fig. 6C). In summary, as opposed to the distinct apoptotic responses, HCT116shERp57 and MDA-MB231 shERp57 cells showed similar changes in proliferation following knockdown of ERp57.

To examine p53-dependence of the proliferation response HCT116 p53 proficient cells were compared to the isogenic p53 deficient cells following ERp57 knockdown. ERp57 has been shown to be involved in regulation and assembly of mammalian target of rapamycin complex 1 (mTORC1). As a measure for mTORC1 activity we monitored phosphorylation of p70S6K at Thr389 in p53 proficient and deficient cells following knockdown of ERp57. We observed decreased activity irrespective of the presence of p53, albeit less pronounced in p53 -/- cells (Fig. 7A). This effect was even stronger when cells were treated with IR in addition. In line with these changes proliferation was significantly decreased in HCT116shERp57 cells in the presence and absence of p53 (Fig. 7B). We further performed clonogenic survival assays to test radiation sensitivity of HCT116 p53 +/+ cells after ERp57 depletion (Fig. 7C). ERp57 depletion alone led to a loss of colony formation as effective as treatment with 3 Gy. In combination however, this effect was amplified between 12- and 15-fold depending on the radiation dose.

\section{DISCUSSION}

One metabolic trait which distinguishes most tumor cells from normal cells is that, despite harsh microenvironmental conditions such as hypoxia, nutrient deprivation and low $\mathrm{pH}$, they must synthesize proteins at a high rate and therefore show an upregulation of the ER folding machinery per se which leads to continuous perturbation of the ER and activation of ERAD. When the ER cannot cope with the level of misfolded proteins, the unfolded protein response (UPR) results in reversible inhibition of protein translation, triggers expression of ER chaperones and may in the case of persistent malfunction tip the balance from pro-survival activity to apoptosis. However, a general benefit for tumor patients through UPR-activation remains highly controversial, as most tumor cells as compared to noncancerous cells bypass apoptotic stress responses during prolonged ER stress and even worse, show increased resistance to chemotherapeutics due to upregulation of ER chaperones, in particular BiP [30-33]. On the other hand, several studies have demonstrated that treatment with ER stressing agents sensitizes tumor cells to alkylating agents like cisplatinum and melphalan [34, 35].
In addition, human A549 lung cancer cells showed ER stress-mediated inhibition of DNA double-strand break repair that enhanced radiosensitivity [36]. Encouraged by previous work [12] which provided evidence that global inhibition of PDI activity mediated by bacitracin can boost the apoptotic effect of chemotherapeutic drugs, our initial hypothesis was that depletion of ERp57 in tumor cells would result in severe ER stress and favour cell death, even more pronounced in combination with IR.

The ER luminal oxidoreductase ERp57 (EC5.3.4.1), also termed GRP58 or PDIA3, is involved in disulfide bond formation of exoproteins. Indeed, ablation of ERp57 triggered apoptosis and magnified the impact of IR and chemotherapeutics in human colon cancer HCT116 cells which was dependent on a crosstalk between the ER and functional $\mathrm{p} 53$. The triple negative breast cancer cell line MDA-MB-231 carrying mutant p53, however, did not show enhanced apoptosis, although the knockdown efficiency was comparable between both cell lines. In our hands ERp57 was not detectable inside the nucleus and thus contradicts other studies that suggested a nuclear role for ERp57 in DNA binding, repair and gene activation [22, 37].

In HCT116 cells, we detected a very distinct cellular response via the PERK branch only, whereas neither IRE1 nor ATF6 showed activation after ERp57 knockdown alone. In addition, we did not observe more than basal protein levels of the ER chaperones calnexin, CRT and the ER master sensor BiP. These findings are in line with previous reports since induction of these proteins is primarily driven by activated ATF6 through binding to ER stress response elements (ERSEs) in their promotor regions [38]. In an earlier study, ERp57 was targeted with specific siRNA in the human endothelial cell line EA. hy926 and, in contrast to our results, decreased the apoptotic response. The authors also noticed an upregulation of $\mathrm{BiP}$ which potentially explains the cell protective effect [39]. Remarkably, the only ER chaperone that was affected by ERp57 depletion in our study was GRP94 [40]. Interestingly, the substrates of GRP94 are believed to be disulfide-bonded proteins exclusively [41] which are prone to misfolding and aggregation after downregulation of the thiol oxidoreductase ERp57. It seems possible that the exclusive upregulation of GRP94 is a specific response to boost the disposal of misfolded client proteins of ERp57 but prevents a full UPR at the same time. A phenotype similar to ours was obtained in a former study of human hepatocellular carcinoma cells where all tested ER chaperones were unaffected by single knockdown and even by double knockdown of ERp57 with PDI accomplished by siRNA gene silencing [42]. The striking phenotypes found in many studies which used toxic chemical ER stress inducers such as thapsigargin or tunicamycin are unlikely to reflect the much more nuanced outcome of ER stress caused by hypoxia, ROS or nutrient deprivation and may thus be grossly misleading [43]. In support of this, a previous study examined the impact of 


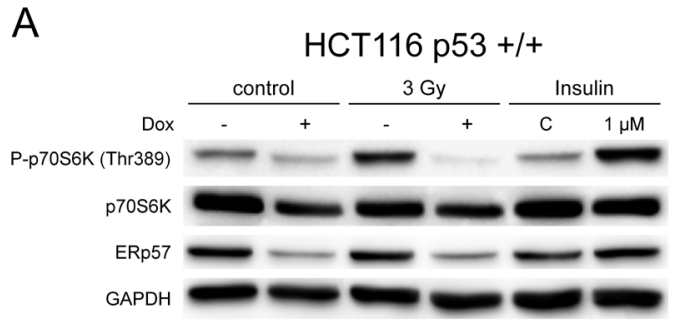

B

$$
\text { HCT116 p53 +/+ }
$$
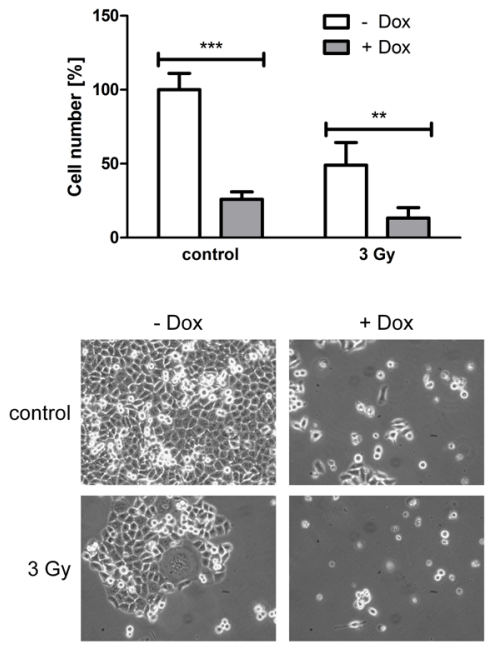

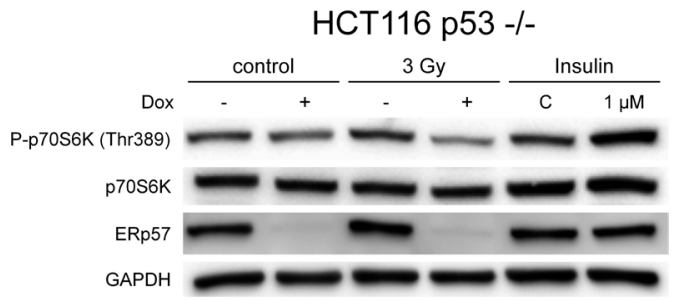

HCT116 p53 -/-
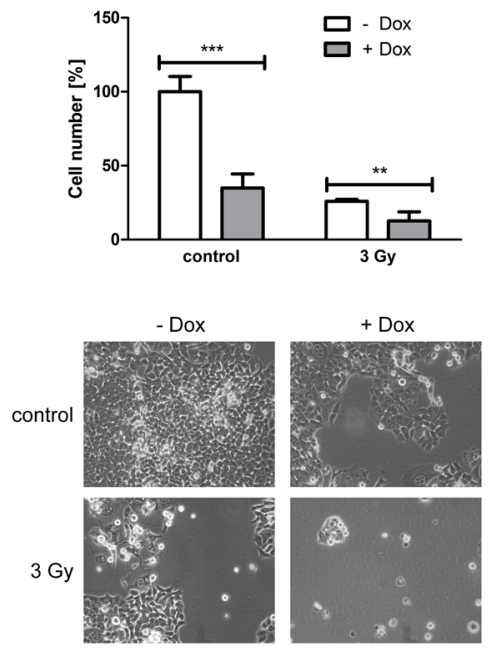

C HCT116 p53 +/+

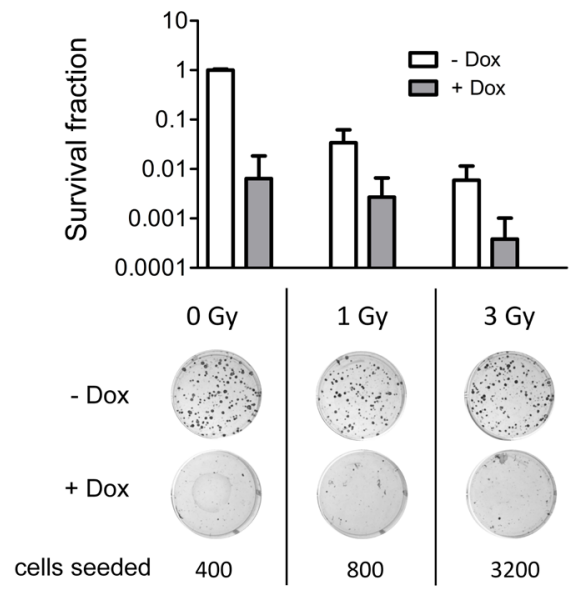

Figure 7: ERp57 triggers proliferation via mTOR activation in a p53-independent manner. A. HCT116 shERp57 p53 +/+ and p53 -/- cells were exposed to 3 Gy $24 \mathrm{~h}$ after induction of ERp57 knockdown. $72 \mathrm{~h}$ after irradiation cell lysates were subjected to Western blotting. mTOR activity was monitored via phosphorylation status of p70S6K at Thr389. As a positive control cells were treated with $1 \mu \mathrm{M}$ insulin for $1 \mathrm{~h}$. B. HCT116 shERp57 p53 +/+ and p53 -/- cells were treated with 3 Gy 4 days after knockdown induction. Following treatment cells were reseeded. Cell counts were determined when the control samples were grown to confluency and normalized to non-induced controls. Images of representative samples taken prior to cell number determination are shown for each subfigure (lower panel). C. Colony formation assay of HCT116 p53 +/+ cells. After induction of ERp57 knockdown, cells were irradiated with 1 or 3 Gy and incubated for 10-14 days. 
individually silenced ER chaperones and postulated very distinct cellular stress responses [44]. Hence, it is possible that the so called "classical" UPR with a full activation of all three branches is either a very transient or a quite rare event in vivo.

Activation of the PERK- eIF2 $\alpha$ pathway results in a global inhibition of cap-dependent protein translation but stimulates translation of the basic leucine-zipper transcription factor ATF4, the master regulator of the ISR. Two of its target genes are GADD34 and CHOP, both are pro-apoptotic factors with short half-lives, but with different action patterns: GADD34 is a cofactor of protein phosphatase 1 (PP1) which dephosphorylates eIF $\alpha$ after prolonged ER stress to initiate apoptosis eventually through an overload of protein translation $[45,46]$. CHOP (also known as GADD153) on the other hand is a transcription factor itself and mediates upregulation of the pro-apoptotic factors PUMA, BIM and DR5 after ER stress [47-49]. Remarkably, although we detected PERK-mediated ER stress in HCT116 cells after ERp57 knockdown followed by a strong PUMA expression, we did not observe any CHOP induction at all. This observation bears the question how p53-dependent apoptosis is linked to ER stress in this scenario. In fact, the ablation of ERp57 led to upregulation of GADD34 which was suggested by others to play an additional, more direct role in apoptosis via phosphorylation of cytoplasmic p53 $[50,51]$. Presumably, a protein interaction of GADD34 with p53 could also compete for binding to PP1. This might explain why we detected phosphorylated eIF $2 \alpha$ despite enhanced GADD34 levels. Moreover, a very recent study described a new aspect of the interplay between disturbed ER homeostasis, cytoplasmic p53 and the $\mathrm{Ca}^{2+}$-dependent mitochondrial apoptosis [52]. The authors demonstrate that activated cytoplasmic wild type p53 can bind and modulate SERCA pumps at the ER, followed by $\left[\mathrm{Ca}^{2+}\right]$ transfer from the ER to mitochondria ultimately leading to cell death. Interestingly, this non-nuclear pro-apoptotic effect of p53 is abolished in mutants defective in DNA binding thus emphasizing the crucial role of the DNA binding domain for pro-apoptotic functions of WT p53. Apart from its function as an anti-apoptotic factor in WT p53 expressing tumor cells, our data provided strong evidence that ERp57 acts as an indispensable growth factor, notably independent of the p53 status of the cell. This effect on proliferation is probably carried out by the cytosolic fraction of ERp57, at least partly through stabilizing the mTORC1 complex to promote phosphorylation of its downstream target S6K1 as reported here and by others [20]. In addition we noticed an enhanced G2-M arrest after ERp57 depletion which is particularly interesting since this is the most radiosensitive phase of the cell cycle [53]. At this point we do not know how ERp57 interferes in cell cycle progression. However, an ER stress induced G2 arrest via PERK was described previously, but in contrast to our results the authors showed a strict dependency on p53 [54]. Instead, cytoplasmic ERp57 may function as an activator of phase-specific cyclin-dependent kinases [55]. Whether any of the contributions of ERp57 requires its oxidoreductive activity or is based on structural properties has not been addressed yet. Unfortunately, it is not possible yet to compare the effects of shRNA-mediated knockdown of ERp57 with a specific inhibitor of ERp57. Clearly, further work is needed to unravel the cellular impact of ERp57 on cell cycle and proliferation which is the object of an ongoing investigation in our lab.

In conclusion, our data demonstrate that depletion of ERp57 leads to a significant induction of p53dependent apoptosis. Although classical ER stress was not detectable at various time points after ERp57 knockdown, we noticed a selective activation of PERK and an upregulation of the ERAD protein GRP94 which may suggest that compensatory effects in certain cell type specific or metabolic situations are possible when ERp57 is downregulated. We also demonstrate that a minor proportion of ERp57 is localized in the cytoplasm where it promotes cell growth and proliferation at least partly via activation of mTOR irrespective of the p53 status. Importantly, p53-dependent and p53-independent effects were synergistic which suggests that the effect of ERp57 inhibition is reduced in a p53-deficient cellular background but not eliminated. Taken together, our study provides compelling evidence that inhibition of ERp57 affects proliferation and apoptosis of cancer cells and that the development of specific inhibitors for ERp57 could help to improve the outcome of future cancer therapies.

\section{MATERIALS AND METHODS}

\section{Reagents, cell culture, transfection and lentiviral transduction}

PERK inhibitor GSK2656157 was from Millipore. All other chemical compounds were from Sigma. MDAMB-231 and HEK293T cells were cultured in highglucose DMEM (Invitrogen, Darmstadt, Germany). HCT116 p53+/+ and isogenic p53-/- cell lines (generously provided by B. Vogelstein, Baltimore, MD) were cultured in McCoy`s 5A medium (Lonza, Basel, Switzerland). Media were supplemented with $10 \%$ FBS and antibiotics. For transient transfection TurboFect (Thermo Scientific) was used. Lentiviral particles were produced in HEK293T cells as described previously [56]. For transduction $2 \times 10^{5}$ cells were incubated with $2 \times 10^{6}$ transduction units for $16-24 \mathrm{~h}$ in the presence of $8 \mu \mathrm{g} / \mu \mathrm{l}$ polybrene. Cells were selected by treatment with the appropriate concentration of puromycin for approximately $10 \mathrm{~d}$. pLKO.1-shRNAERp57 tet-on (tetracycline inducible) contained the sequence GGAATAGTCCCATTAGCAAAG of ERp57 mRNA (GenBank acc. no. NM_005313). Gene knockdown was induced by addition of $250 \mathrm{ng} / \mathrm{ml}$ doxycycline. 


\section{Apoptosis quantification}

Caspase-3 activity was quantified as described previously [57]. Release of fluorescent 7-amino-4methylcoumarin (AMC) after cleavage from Ac-DEVDAMC was quantified over $4 \mathrm{~h}$. Apoptosis was also quantified by flow cytometry with Annexin V and PI. For staining $1 \times 10^{5}$ cells were incubated with $80 \mu \mathrm{g} / \mathrm{ml}$ PI and $9.6 \mu \mathrm{g} / \mathrm{ml}$ Annexin V conjugated to PacificBlue (No. 640917, Biolegend, San Diego, CA, USA) in Annexin $\mathrm{V}$ binding buffer (No. 422201, Biolegend) for $15 \mathrm{~min}$ at room temperature. Cells were analysed on a FACS Canto II (BD Biosciences, Franklin Lakes, NJ, USA). 10000 cells per sample were analysed. Data analysis was performed using FCS Express 4 Flow software (De Novo Software, Los Angeles, CA, USA).

\section{Cell cycle analysis}

For cell cycle analysis $4 \times 10^{5}$ cells treated as indicated were lysed in $400 \mu \mathrm{l}$ hypotonic citrate buffer $(0.1 \%$ sodium citrate, $0.1 \%$ Triton $\mathrm{X}-100)$ containing $50 \mu \mathrm{g} / \mathrm{ml}$ PI for 30-60 min. Following staining, intact nuclei (as discriminated by PE-area versus PE-width gating) were directly analysed for DNA content by FACS. 30000 (HCT116) or 50000 (MDA-MB-231) nuclei per sample were analysed.

\section{Western blotting and immunoprecipitation}

Whole cell extracts were prepared in RIPA lysis buffer and processed for Western blotting essentially as described previously [57]. Monoclonal antibodies used for $\mathrm{p} 53$ and MDM2 were from Millipore (Billerica, MA, USA) or Santa Cruz (Dallas, TX, USA), respectively. All other primary antibodies were polyclonal. Detailed antibody information is available from the authors upon request. For co-IP, $300 \mu \mathrm{g}$ of whole cell lysates were incubated with $0.5 \mu \mathrm{g}$ p53 antibody. Control IPs were performed with the same amount of mouse $\operatorname{IgG} 2$ a isotype control.

\section{Cell proliferation}

To assess cell proliferation $2 \times 10^{5} \mathrm{HCT} 116$ or $3 \times 10^{5}$ MDA-MB-231 cells were seeded in P60 cell culture dishes. To study effects of chemotherapy on proliferation, $1 \times 10^{5}$ cells were reseeded in P60 cell culture dishes following incubation with etoposide or 5 -fluorouracil on day 5 for $4 \mathrm{~h}$. To assess the influence of irradiation on proliferation, $1 \times 10^{5}$ cells were reseeded in P60 cell culture dishes $24 \mathrm{~h}$ after irradiation with $3 \mathrm{~Gy}$ on day 4. When control samples were confluent, cells were stained with trypan blue and viable cells counted using a Cellometer ${ }^{\mathrm{TM}}$ Auto T4 (Peqlab).

\section{Clonogenic survival assay}

Depending on the experiment planned, 100 or up to 6400 cells in exponential growth were seeded in collagen precoated 6 well dishes. ERp57 knockdown was induced and cells were incubated for $16 \mathrm{~h}$. The cells were irradiated with 1 or 3 Gy and incubated for $10 \mathrm{~d}$. Cells were fixed with $0.25 \%$ paraformaldehyde and $70 \%$ ethanol and stained with Coomassie. Colonies of more than 50 cells were counted manually. Survival was calculated as number of colonies divided by cells seeded x plating efficiency as described previously [58].

\section{Immunofluorescence}

To study the subcellular localization of ERp57, $1 \times 10^{5}$ HCT116 cells were seeded onto glass cover slides coated with rat collagen-I (Biozol, Eching, Germany). pEGFP-N1-ERp57 encoding ERp57 with a C-terminal GFP was generated by PCR cloning. Following transfection cells were treated as indicated, incubated with $1 \mu \mathrm{M}$ ER-TrackerTM Blue-White DPX (Invitrogen) and $5 \mu \mathrm{M}$ DRAQ5 ${ }^{\mathrm{TM}}$ (Thermo Scientific), fixed with $4 \%$ paraformaldehyde and analysed using a Zeiss LSM510 confocal microscope.

\section{Cellular fractionation}

To separate the cytoplasm from other cellular compartments HCT116 cells were suspended in hypertonic buffer (5 mM sucrose, $1 \mathrm{mM}$ HEPES $\mathrm{pH}$ 7.4) containing $50 \mu \mathrm{g} / \mathrm{ml}$ digitonin for $90 \mathrm{sec}$. The cytoplasmic fraction was collected following centrifugation with $800 \times \mathrm{g}$ for 1 min. Residual compartments were lysed in RIPA.

\section{XBP1 splicing}

Total RNA from HCT116 cells was prepared using RNeasy Mini Kit (Qiagen, Hilden, Germany). Reverse transcription was performed using the iScript ${ }^{\mathrm{TM}}$ Select cDNA Synthesis Kit (Bio-Rad, Hercules, CA, USA). For detection of spliced and unspliced XBP1 cDNA PCR was performed using forward primer 5'-AAACAGAGTAGCAGCTCAGACTGC-3' and reverse primer 5'-CCTTCTGGGTAGACCTCTGGGAG-3'. The PCR products of XBP1 and $\beta$-actin were visualized on $2.5 \%$ agarose gels.

\section{Reporter gene assays}

$5 \times 10^{4}$ cells were seeded into 24 -well plates. $24 \mathrm{~h}$ after knockdown induction, the cells were either co-transfected with $500 \mathrm{ng}$ of the reporter plasmid p5xATF6-GL3 (\#11976, Addgene) and 100 ng pGL4.74 (expressing renilla luciferase) or transfected with pFLAG-XBP1u-FLuc (\#31239, Addgene). 16-24 h after 
transfection cells were treated as indicated. Firefly and renilla luciferase activities were quantified using a DualLuciferase Reporter Assay (Promega) on a TD 20/20 luminometer (Turner Designs, Sunnyvale, CA, USA).

\section{Statistical analysis}

All experimental results were confirmed in at least two independent experiments unless otherwise indicated. Data presented in bar graphs include at least three independent samples. Bars represent mean plus standard deviation. Comparison of two groups was performed by application of Student's $t$-test using GraphPad Prism 5 (GraphPad Software, San Diego, CA, USA). Data were expressed as the mean + s.d. In all figures $*$ indicates $p<0,05$, while $* *$ indicates a $p$-value of $<0,01$ and $* * * p<0,001$.

\section{ACKNOWLEDGMENTS}

The study was supported by the Deutsche Forschungsgemeinschaft Research Training Group 1739 (GRK1739). The authors are grateful to Bert Vogelstein, Howard Hughes Medical Institute, Baltimore, Maryland, for provision of HCT116 p53-/- cells. The authors are greatly indebted to George Iliakis, Institut für Strahlenbiologie, Universität Duisburg-Essen, for making all radiation equipment available to us. Verena Jendrossek, Institut für Zellbiologie, Universität Duisburg-Essen, is acknowledged for sharing reagents and for helpful discussions. The authors also thank Harald Engler, Institut für Medizinische Psychologie, Universität DuisburgEssen, for help with the FACS analysis.

\section{CONFLICTS OF INTEREST}

The authors declare no conflict of interest.

\section{GRANT SUPPORT}

This study was supported by the Deutsche Forschungsgemeinschaft Research Training Group GRK1739.

\section{REFERENCES}

1. Ellgaard L, Molinari M, Helenius A. Setting the standards: quality control in the secretory pathway. Science (New York, N.Y.). 1999; 286:1882-1888.

2. Nakatsukasa K, Kamura T, Brodsky JL. Recent technical developments in the study of ER-associated degradation. Current opinion in cell biology. 2014; 29C:82-91.

3. Ruggiano A, Foresti O, Carvalho P. Quality control: ER-associated degradation: protein quality control and beyond. The Journal of cell biology. 2014; 204:869-879.
4. Zhang K, Kaufman RJ. The unfolded protein response: a stress signaling pathway critical for health and disease. Neurology. 2006; 66:S102-9.

5. Clarke HJ, Chambers JE, Liniker E, Marciniak SJ. Endoplasmic Reticulum Stress in Malignancy. Cancer cell. 2014; 25:563-573.

6. Healy SJ, Gorman AM, Mousavi-Shafaei P, Gupta S, Samali A. Targeting the endoplasmic reticulum-stress response as an anticancer strategy. European journal of pharmacology. 2009; 625:234-246.

7. Harding HP, Zhang Y, Zeng H, Novoa I, Lu PD, Calfon M, Sadri N, Yun C, Popko B, Paules R, Stojdl DF, Bell JC, Hettmann T, et al. An integrated stress response regulates amino acid metabolism and resistance to oxidative stress. Molecular cell. 2003; 11:619-633.

8. Ma Y, Hendershot LM. The role of the unfolded protein response in tumour development: friend or foe? Nature reviews. Cancer. 2004; 4:966-977.

9. Luo S, Baumeister P, Yang S, Abcouwer SF, Lee AS. Induction of Grp78/BiP by translational block: activation of the Grp78 promoter by ATF4 through and upstream ATF/CRE site independent of the endoplasmic reticulum stress elements. The Journal of biological chemistry. 2003; 278:37375-37385.

10. Luo B, Lee AS. The critical roles of endoplasmic reticulum chaperones and unfolded protein response in tumorigenesis and anticancer therapies. Oncogene. 2013; 32:805-818.

11. Ranganathan AC, Zhang L, Adam AP, Aguirre-Ghiso JA. Functional coupling of $\mathrm{p} 38$-induced up-regulation of $\mathrm{BiP}$ and activation of RNA-dependent protein kinase-like endoplasmic reticulum kinase to drug resistance of dormant carcinoma cells. Cancer research. 2006; 66:1702-1711.

12. Lovat PE, Corazzari M, Armstrong JL, Martin S, Pagliarini V, Hill D, Brown AM, Piacentini M, BirchMachin MA, Redfern CP. Increasing melanoma cell death using inhibitors of protein disulfide isomerases to abrogate survival responses to endoplasmic reticulum stress. Cancer research. 2008; 68:5363-5369.

13. Xu S, Sankar S, Neamati N. Protein disulfide isomerase: a promising target for cancer therapy. Drug discovery today. 2014; 19:222-240.

14. Banerjee R, Pace NJ, Brown DR, Weerapana E. $1,3,5$-Triazine as a modular scaffold for covalent inhibitors with streamlined target identification. Journal of the American Chemical Society. 2013; 135:2497-2500.

15. Hoffstrom BG, Kaplan A, Letso R, Schmid RS, Turmel GJ, Lo DC, Stockwell BR. Inhibitors of protein disulfide isomerase suppress apoptosis induced by misfolded proteins. Nature chemical biology. 2010; 6:900-906.

16. Xu S, Butkevich AN, Yamada R, Zhou Y, Debnath B, Duncan R, Zandi E, Petasis NA, Neamati N. Discovery of an orally active small-molecule irreversible inhibitor of protein disulfide isomerase for ovarian cancer treatment. Proceedings of the National Academy of Sciences of the United States of America. 2012; 109:16348-16353. 
17. Zhang Y, Kozlov G, Pocanschi CL, Brockmeier U, Ireland BS, Maattanen P, Howe C, Elliott T, Gehring K, Williams DB. ERp57 does not require interactions with calnexin and calreticulin to promote assembly of class I histocompatibility molecules, and it enhances peptide loading independently of its redox activity. The Journal of biological chemistry. 2009; 284:10160-10173.

18. Jessop CE, Chakravarthi S, Garbi N, Hammerling GJ, Lovell S, Bulleid NJ. ERp57 is essential for efficient folding of glycoproteins sharing common structural domains. The EMBO journal. 2007; 26:28-40.

19. Kozlov G, Maattanen P, Schrag JD, Pollock S, Cygler M, Nagar B, Thomas DY, Gehring K. Crystal structure of the bb' domains of the protein disulfide isomerase ERp57. Structure (London, England: 1993). 2006; 14:1331-1339.

20. Ramirez-Rangel I, Bracho-Valdes I, Vazquez-Macias A, Carretero-Ortega J, Reyes-Cruz G, Vazquez-Prado J. Regulation of mTORC1 complex assembly and signaling by GRp58/ERp57. Molecular and cellular biology. 2011; 31:1657-1671.

21. Guo GG, Patel K, Kumar V, Shah M, Fried VA, Etlinger JD, Sehgal PB. Association of the chaperone glucose-regulated protein 58 (GRP58/ER-60/ERp57) with Stat 3 in cytosol and plasma membrane complexes. Journal of interferon \& cytokine research : the official journal of the International Society for Interferon and Cytokine Research. 2002; 22:555-563.

22. Krynetskaia NF, Phadke MS, Jadhav SH, Krynetskiy EY. Chromatin-associated proteins HMGB1/2 and PDIA3 trigger cellular response to chemotherapy-induced DNA damage. Molecular cancer therapeutics. 2009; 8:864-872.

23. Chichiarelli S, Ferraro A, Altieri F, Eufemi M, Coppari S, Grillo C, Arcangeli V, Turano C. The stress protein ERp57/ GRP58 binds specific DNA sequences in HeLa cells. Journal of cellular physiology. 2007; 210:343-351.

24. Panaretakis $\mathrm{T}$, Kepp O, Brockmeier U, Tesniere A, Bjorklund AC, Chapman DC, Durchschlag M, Joza N, Pierron G, van Endert P, Yuan J, Zitvogel L, Madeo F, et al. Mechanisms of pre-apoptotic calreticulin exposure in immunogenic cell death. The EMBO journal. 2009; 28:578-590.

25. Nemere I, Garbi N, Hammerling GJ, Khanal RC. Intestinal cell calcium uptake and the targeted knockout of the 1,25D3-MARRS (membrane-associated, rapid response steroid-binding) receptor/PDIA3/Erp57. The Journal of biological chemistry. 2010; 285:31859-31866.

26. Corazzari M, Lovat PE, Armstrong JL, Fimia GM, Hill DS, Birch-Machin M, Redfern CP, Piacentini M. Targeting homeostatic mechanisms of endoplasmic reticulum stress to increase susceptibility of cancer cells to fenretinide-induced apoptosis: the role of stress proteins ERdj5 and ERp57. British journal of cancer. 2007; 96:1062-1071.

27. Tabas I, Ron D. Integrating the mechanisms of apoptosis induced by endoplasmic reticulum stress. Nature cell biology. 2011; 13:184-190.
28. Atkins C, Liu Q, Minthorn E, Zhang SY, Figueroa DJ, Moss K, Stanley TB, Sanders B, Goetz A, Gaul N, Choudhry AE, Alsaid H, Jucker BM, et al. Characterization of a novel PERK kinase inhibitor with antitumor and antiangiogenic activity. Cancer research. 2013; 73:1993-2002.

29. Chichiarelli S, Gaucci E, Ferraro A, Grillo C, Altieri F, Cocchiola R, Arcangeli V, Turano C, Eufemi M. Role of ERp57 in the signaling and transcriptional activity of STAT3 in a melanoma cell line. Archives of Biochemistry and Biophysics. 2010; 494:178-183.

30. Belfi CA, Chatterjee S, Gosky DM, Berger SJ, Berger NA. Increased sensitivity of human colon cancer cells to DNA cross-linking agents after GRP78 up-regulation. Biochemical and biophysical research communications. 1999; 257:361-368.

31. Gosky D, Chatterjee S. Down-regulation of topoisomerase II alpha is caused by up-regulation of GRP78. Biochemical and biophysical research communications. 2003; 300:327-332.

32. Jamora C, Dennert G, Lee AS. Inhibition of tumor progression by suppression of stress protein GRP78/BiP induction in fibrosarcoma B/C10ME. Proceedings of the National Academy of Sciences of the United States of America. 1996; 93:7690-7694.

33. Shen J, Hughes C, Chao C, Cai J, Bartels C, Gessner T, Subjeck J. Coinduction of glucose-regulated proteins and doxorubicin resistance in Chinese hamster cells. Proceedings of the National Academy of Sciences of the United States of America. 1987; 84:3278-3282.

34. Chatterjee S, Hirota H, Belfi CA, Berger SJ, Berger NA. Hypersensitivity to DNA cross-linking agents associated with up-regulation of glucose-regulated stress protein GRP78. Cancer research. 1997; 57:5112-5116.

35. Yamada M, Tomida A, Yun J, Cai B, Yoshikawa H, Taketani Y, Tsuruo T. Cellular sensitization to cisplatin and carboplatin with decreased removal of platinum-DNA adduct by glucose-regulated stress. Cancer chemotherapy and pharmacology. 1999; 44:59-64.

36. Yamamori T, Meike S, Nagane M, Yasui H, Inanami O. ER stress suppresses DNA double-strand break repair and sensitizes tumor cells to ionizing radiation by stimulating proteasomal degradation of Rad51. FEBS letters. 2013; 587:3348-3353.

37. Grillo C, D'Ambrosio C, Scaloni A, Maceroni M, Merluzzi S, Turano C, Altieri F. Cooperative activity of Ref-1/APE and ERp57 in reductive activation of transcription factors. Free radical biology \& medicine. 2006; 41:1113-1123.

38. Baumeister P, Luo S, Skarnes WC, Sui G, Seto E, Shi Y, Lee AS. Endoplasmic reticulum stress induction of the Grp78/BiP promoter: activating mechanisms mediated by YY1 and its interactive chromatin modifiers. Molecular and cellular biology. 2005; 25:4529-4540.

39. Xu D, Perez RE, Rezaiekhaligh MH, Bourdi M, Truog WE. Knockdown of ERp57 increases BiP/GRP78 induction 
and protects against hyperoxia and tunicamycin-induced apoptosis. American journal of physiology. Lung cellular and molecular physiology. 2009; 297:L44-51.

40. Christianson JC, Shaler TA, Tyler RE, Kopito RR. OS-9 and GRP94 deliver mutant alpha1-antitrypsin to the Hrd1SEL1L ubiquitin ligase complex for ERAD. Nature cell biology. 2008; 10:272-282.

41. Marzec M, Eletto D, Argon Y. GRP94: An HSP90-like protein specialized for protein folding and quality control in the endoplasmic reticulum. Biochimica et biophysica acta. 2012; 1823:774-787.

42. Rutkevich LA, Cohen-Doyle MF, Brockmeier U, Williams DB. Functional relationship between protein disulfide isomerase family members during the oxidative folding of human secretory proteins. Molecular biology of the cell. 2010; 21:3093-3105.

43. Wang M, Kaufman RJ. The impact of the endoplasmic reticulum protein-folding environment on cancer development. Nature reviews. Cancer. 2014; 14:581-597.

44. Eletto D, Maganty A, Eletto D, Dersh D, Makarewich C, Biswas C, Paton JC, Paton AW, Doroudgar S, Glembotski CC, Argon Y. Limitation of individual folding resources in the ER leads to outcomes distinct from the unfolded protein response. Journal of cell science. 2012; 125:4865-4875.

45. Hollander MC, Zhan Q, Bae I, Fornace AJ Jr. Mammalian GADD34, an apoptosis- and DNA damage-inducible gene. The Journal of biological chemistry. 1997; 272:13731-13737.

46. Brush MH, Weiser DC, Shenolikar S. Growth arrest and DNA damage-inducible protein GADD34 targets protein phosphatase 1 alpha to the endoplasmic reticulum and promotes dephosphorylation of the alpha subunit of eukaryotic translation initiation factor 2. Molecular and cellular biology. 2003; 23:1292-1303.

47. Yamaguchi H, Wang HG. CHOP is involved in endoplasmic reticulum stress-induced apoptosis by enhancing DR5 expression in human carcinoma cells. The Journal of biological chemistry. 2004; 279:45495-45502.

48. Puthalakath H, O'Reilly LA, Gunn P, Lee L, Kelly PN, Huntington ND, Hughes PD, Michalak EM, McKimmBreschkin J, Motoyama N, Gotoh T, Akira S, Bouillet P, et al. ER stress triggers apoptosis by activating BH3-only protein Bim. Cell. 2007; 129:1337-1349.
49. Galehdar Z, Swan P, Fuerth B, Callaghan SM, Park DS, Cregan SP. Neuronal apoptosis induced by endoplasmic reticulum stress is regulated by ATF4-CHOP-mediated induction of the Bcl-2 homology 3-only member PUMA. The Journal of neuroscience : the official journal of the Society for Neuroscience. 2010; 30:16938-16948.

50. Yagi A, Hasegawa Y, Xiao H, Haneda M, Kojima E, Nishikimi A, Hasegawa T, Shimokata K, Isobe K. GADD34 induces $\mathrm{p} 53$ phosphorylation and p21/WAF1 transcription. Journal of cellular biochemistry. 2003; 90:1242-1249.

51. Su ZZ, Emdad L, Sarkar D, Randolph A, Valerie K, Yacoub A, Dent P, Fisher PB. Potential molecular mechanism for rodent tumorigenesis: mutational generation of Progression Elevated Gene-3 (PEG-3). Oncogene. 2005; 24:2247-2255.

52. Giorgi C, Bonora M, Sorrentino G, Missiroli S, Poletti F, Suski JM, Galindo Ramirez F, Rizzuto R, Di Virgilio F, Zito E, Pandolfi PP, Wieckowski MR, Mammano F, et al. p53 at the endoplasmic reticulum regulates apoptosis in a Ca2+-dependent manner. Proceedings of the National Academy of Sciences of the United States of America. 2015; 112:1779-1784.

53. Pawlik TM, Keyomarsi K. Role of cell cycle in mediating sensitivity to radiotherapy. International journal of radiation oncology, biology, physics. 2004; 59:928-942.

54. Bourougaa K, Naski N, Boularan C, Mlynarczyk C, Candeias MM, Marullo S, Fahraeus R. Endoplasmic reticulum stress induces G2 cell-cycle arrest via mRNA translation of the p53 isoform p53/47. Molecular cell. 2010; 38:78-88.

55. Chung JH, Bunz F. Cdk2 is required for p53-independent G2/M checkpoint control. PLoS genetics. 2010; 6:e1000863.

56. Brockmeier U, Platzek C, Schneider K, Patak P, Bernardini A, Fandrey J, Metzen E. The function of hypoxia-inducible factor (HIF) is independent of the endoplasmic reticulum protein OS-9. PloS one. 2011; 6:e19151.

57. Janke K, Brockmeier U, Kuhlmann K, Eisenacher M, Nolde J, Meyer HE, Mairbaurl H, Metzen E. Factor inhibiting HIF-1 (FIH-1) modulates protein interactions of apoptosis-stimulating $\mathrm{p} 53$ binding protein 2 (ASPP2). Journal of cell science. 2013; 126:2629-2640.

58. Franken NA, Rodermond HM, Stap J, Haveman J, van Bree C. Clonogenic assay of cells in vitro. Nature protocols. 2006; 1:2315-2319. 